\title{
Web Practices for Sustainable Development of Logistics Systems in Bulgarian Enterprises
}

\section{Nikolay Dragomirov}

\section{Summary}

The internet era has revealed unlimited potential for innovation and sustainable development in the web space. In the field of logistics this means that the internet gives new opportunities for collaboration and building new logistics systems with suppliers and customers. Modern, webbased software solutions are very flexible to market needs and offer a variety of options for applying many supply chain management practices. Among these are website solutions that offer plenty of alternatives not only to represent company products and services but also to automate some of the business processes. Now the business organisations have unlimited alternatives to develop their new models covering their information, logistics and marketing needs. The article presents some of the web-based practices related to the general problems of logistics management in Bulgarian enterprises. The results are based on data collected by a survey and cover the main problems of communication with customers and suppliers in the supply chain, logistics service providers and integration of the internal supply chain processes by the website software solutions used in the organisation. The main findings of the article are based on the relatively low level of usage of the full potential of modern information systems.

Keywords: web, digitalisation, logistics JEL: M15, M19

\section{INTRODUCTION}

nternet development is an undeniable process that leads to the emergence of new and sustainable business models based on high technology and knowledge. The emergence of digital networks and their widespread use by people and organisations forms a radically different and new environment for communication and information exchange. The global internet network offers a new beginning for doing business. It takes the shape of virtual communication, followed by real material flows. Thus, the concept of digital companies, which are integrators of processes in a virtual environment and a determining factor for the movement of material flows, is born. They are a new kind of business unit representing the natural development of the use of information systems and technologies in business. Typical of this type of structure is that relationships with clients, suppliers and employees, and basic business processes in the organisation and supply chain are

\footnotetext{
* University of National and World Economy - Sofia, Department of Logistics and Supply Chains
} 


\section{Articles}

assisted and managed by information systems and technologies (Laudon \& Laudon, 2012, p. 11). The automatisation leads to better performance, accuracy, reliability, traceability, etc. Now the time and space are not a problem and they become alternative factors affecting competitive advantage related to management of information flows in the supply chain. New market spaces are created in which customers do not know the company's location, and the physical location is not important now (Katrandzhiev, 2008, p. 291) and creates sustainable conditions for time advantages, communication, unlimited size and scope organisations, globalisation, and high efficiency processes. The information security for these companies could be a possible challenge because information security management systems are rarely applied by the logistics industry (Vodenicharova, 2016).

Typical for a digital company is that relationships with customers, suppliers and employees are supported and managed by information systems and technologies, which speeds up the flow of information between them and is a prerequisite for accelerating the material flows in the supply chain. For digital companies it is necessary that the core business processes in the organisation and the supply chain be covered by information systems. Digital companies have the highest level of partnership in the supply chain, and they operate as closely as possible. At this stage of development and integration there is no talk of exchanging information because information is a common asset. This is a prerequisite for digitalisation and efficient management of material flows in the supply chain, which will lead to sustainable development because digitalisation significantly correlates with the sustainable development components (Jovanović et al., 2018).
Web Practices for Sustainable Development of Logistics

Systems in Bulgarian Enterprises

In this context, the evolution of web platforms, especially e-commerce related ones, is of interest. The reason is that e-commerce is definitely increasing along with increased internet access, characterised by an increase in the proportion of mobile shoppers and the predominance of small-value purchases (PostNord, 2017). Organisations now have more than ever the opportunity to reach buyers if they can meet their requirements for freedom of choice, in order for them to create their order and have it delivered to them in the way they prefer.

It is important to note that the availability of goods is one of the main reasons for switching to e-commerce (Kadłubek, 2015), which is a challenge for the supply chain and the delivery itself (Saskia et al., 2016). It is no coincidence that e-commerce is not just a new distribution channel, because it is a change that impacts logistics activities such as warehousing and inventory management (Żurek, 2015). The growth of this new market can also be measured quantitatively, as for the EU-28 (the 28 Member States of the European Union) for the period 2008-2016, the share of enterprises that have sold online has increased by $7 \%$, with the trend being steady and observed in all types of enterprises - large, medium and small (Eurostat, 2017).

A few years ago the primary function of web-based systems was the presentation of products and services in the virtual space without being interested in integration with other suppliers in the supply chain, but nowadays these shortcomings are being increasingly addressed, transforming them into complete web solutions with the goal of setting the conditions for implementing the ideas for digital companies. The evolutionary development of web technologies is driven by their use in practice, first mainly for presenting products in the web space, leading to their transformation into a solution for 


\section{Articles}

creating sustainable logistic systems in the supply chain, and this is shown in Fig. 1.This evolution reveals a potential for transformation of traditional web systems into supply chain management software consisting of integrated information systems of the supply chain partners.

Figure 1. E-commerce evolution within the organisation (Dragomirov, 2015)

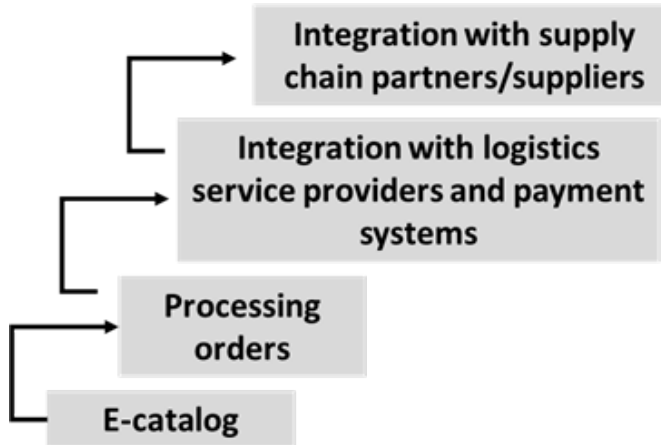

The efficiency of supply chain operations managed in any virtual way is a challenge because the success of every supply chain partner depends on the performance of the slowest participant and reflects the sustainability of the whole system. The solution could be found in the usage of a variety of information technologies that are leading to digitalisation and digital transformation. It is important to notice that digitalisation and digital transformation present opportunities for improvement of the effectiveness and efficiency in SCM (Boyanov, 2019). It is also important that there should be no great delay in the management and physical movement of material flows compared to the management of information flows, and this is another logistics challenge.

\section{METHODOLOGY}

The results of the research are based on a survey conducted among the main participants in the logistics processes, namely the commercial and processing/manufacturing enterprises in Bulgaria. The aim of the study is to identify the main practices in the use of web systems in the field of logistics activities management. Despite the wide potential scope of the study, a limited number of indicators are used in this article to cover only important facts about present practices to be used for further research. In the survey Likert scale questions are mainly used (1 Strongly disagree, 2 - Somewhat disagree, 3 Neither agree nor disagree, 4 - Somewhat agree, 5 - Strongly agree) and in the current article the following main research indicators are covered:

- Relationship management with customers, trade partners and suppliers degree of integration of the company web site to support customers, trading and supplier processes.

- Integration with delivery companies and payment systems - Degree of integration with courier organisations in the automation of document preparation and communication activities as well as connection to online payment systems.

- Support of intra-organisational logistics processes and the overall performance degree of integration with other systems in the organisation to support logistics processes, as well as a general assessment of the system's operation and the need for improvement.

With these basic research indicators is outlined the level of usage of web technologies in the Bulgarian enterprises in the field of logistics for developing sustainable systems and future research areas are defined.

\section{RESULTS AND DISCUSSION}

The number of respondents involved in the analysis is approximately 150 , with $54 \%$ small businesses (up to 49 employees), $27 \%$ medium (from 50 to 249 ), and $19 \%$ large enterprises (over 250 employees). 


\section{Articles}

According to the ownership, the share of foreign companies, operating on the territory of the country is almost $20 \%$, with the rest, $80 \%$, being entirely Bulgarian companies. What is of interest for the first indicator Relationship management with customers, trade partners and suppliers are the practices of communication with clients and suppliers. The respondents in the sample indicate that they use traditional communication forms and to a lesser extent, innovative ones, which explains somewhat the results for the individual indicators in the survey. A summary
Web Practices for Sustainable Development of Logistics

Systems in Bulgarian Enterprises

of the answers to the question "How do you communicate with your clients and suppliers?" is outlined in Table 1. The high numbers for some of the forms of communication can be explained by organisational culture (Madanchian \& Taherdoost, 2016), in which the organisation operates. It is also related to the digital transformation of the organisations and these problems accordingly (Slavova, 2016) could be studied in these categories consumer behaviour, business operations and business model transformation, which reveals a potential for future research.

Table 1. Answers to the question "How do you communicate with your customers and suppliers?" (Respondents gave several answers)

\begin{tabular}{|l|l|l|l|l|}
\hline & Personal meetings & Phone & E-mail & $\begin{array}{l}\text { Through the organisation's } \\
\text { website }\end{array}$ \\
\hline Clients & $73 \%$ & $88 \%$ & $78 \%$ & $30 \%$ \\
\hline Suppliers & $66 \%$ & $91 \%$ & $80 \%$ & $17 \%$ \\
\hline
\end{tabular}

These results reveal a low level of digitalisation and digital transformation and companies have different approaches to follow in order to improve it. It is important that under the global trends the diffusion of the web technologies and practices in the country is possible to follow an S-shape pattern as it is discovered by (Papagiannidis et al., 2015) for some web technologies, which is related to a potential intensive growth in the future and the companies have to be prepared for this process.

In general, from the results of the survey it can be determined that the use of web solutions in the field of relationship management with customers, trade partners and suppliers is very low and unsatisfactory. For most of the questions related to the use of the company web site, the average score is between 2 and 3 . The results of all responses are shown in Figure 2. The respondents gave the highest rate of 4.17 to the application related to the presentation of products and services, and it should be noted that this question has the lowest standard deviation of 1.19. The second answer (receiving customer orders) is for receiving customer orders, with an average value of 3.42 . The low mean values of the answers to this question suggest that Bulgarian organisations are still at an early stage of development in the realm of e-commerce, business e-catalogues and order processing. The low scores on multiple issues and the small differences between the answers to different questions shows with high credibility that organisations do not make full use of the capabilities of web-based solutions. A positive point is the desire to shift phone communication with customers to a variety of web solutions, which signals a drive for introducing innovation and automatisation of customer service. 
Figure 2. Answers to the question - What is the main purpose of your company website? (related to Relationship management with customers, trade partners and suppliers)

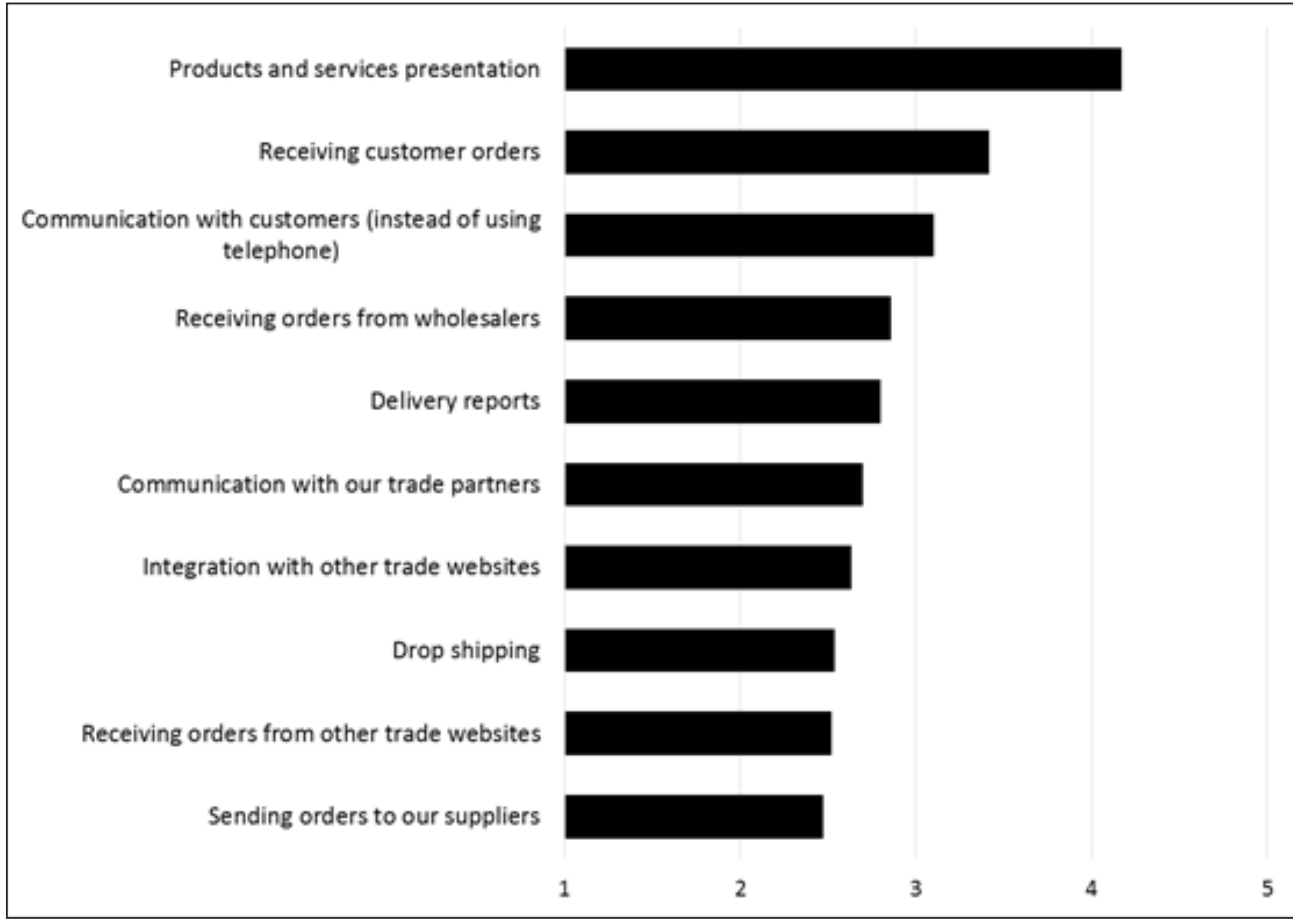

The results are similar in the answers to the request "Please rate the following statements for your company website". Only one of the claims has an average score of more than 3 ; the others are again between 2 or 3 . The results for all statements are outlined in Figure 3. The intent to integrate with social networks is to some extent dictated by the opportunities for expanding sales channels but the other low ratings confirm the conclusions of the previous figure. Bulgarian companies have few web systems applications to support logistics processes and still prefer traditional methods such as telephone communication, face to face communication, and a low level of integration with the information systems of suppliers, business partners, etc. Part of the reason for this can be found in the established commercial practices in the country and the impossibility of introducing such innovations by individual organisations because success requires such an approach by the other participants in the supply chain. In order for new practices to be introduced, it is necessary for the companies to realise that the environment has changed. Due to the fast development and large influence of e-commerce, logistics have greatly changed compared to several decades ago ( $\mathrm{Yu}$ et al., 2016). For example, modern logistics information systems provide flexibility to integrate with other information systems through a standardised API (Application Programming Interface) that allows for the necessary data to be exchanged to implement logistics activities. This is an approach that allows different types of developers and partners to easily integrate with the corporate system (HCL, 2014), which is why it is widely applied in different business areas. Unfortunately, these options are not being used, and there is a potential for conducting further research to identify the causes. 
Figure 3. Answers to the request - Please rate the following statements for your company website (related to Relationship management with customers, trade partners and suppliers)

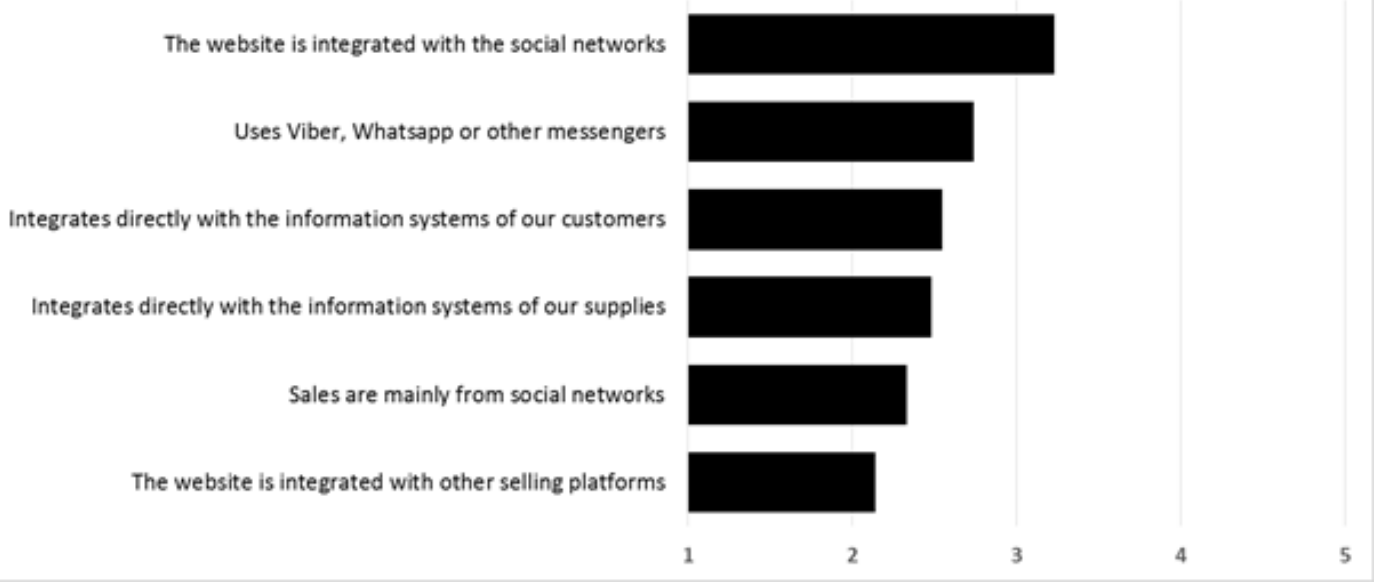

Any form of outsourcing integration especially in the e-commerce is positive and has a future for the business organisation. Like the very forward-looking and promising trend in e-commerce is using an outsource fulfilment service, which usually minimises the costs associated with logistics and can allow more time to be dedicated to marketing, branding, etc. (Kawa, 2017)

The integration with delivery companies and payment systems reveals the level of informational collaboration with other important supply chain members. Unfortunately, the results again show untapped potential. The average rating of the use of web systems for "Document preparation for delivery" is only 2.90 and the possibility of the information system to communicate directly with the delivery companies is rated at 2.54. In terms of payment practices, receiving payments through the web system is put at only 2.49 , which could be a result of the non-popularity of the practice whereby the customer pays before delivery.

The last research indicator covers the support of intra-organisational logistics processes and the overall performance of web systems. It is important to mention that e-business changes the management of logistics functions. Inventory management for online e-commerce is a challenge for warehousing (Patil \& Divekar, 2014), especially for picking performance (Boysen et al., 2018), which is the activity that has the highest proportion of warehousing costs (Richards, 2014). The right solution requires integration between logistics and other business functions in the internal supply chain. That is why platforms have appeared integrating marketplaces, shipping couriers (logistics service providers), and accounting platforms (Veeqo, 2018), and their features cover a variety of warehousing activities and problems, including multiple warehouses, product location, automatic identification etc.

Unfortunately, the practice in Bulgarian enterprises is not aimed at following global trends and the web systems are still poorly integrated with the management of the logistics activities in the internal supply chain. Summarised results of the answers to the question - 'What is the main purpose of your company website?' are shown in Figure 4. 


\section{Articles}

Figure 4. Answers to the question - What is the main purpose of your company website? (related to the support of intra-organisational logistics processes and the overall performance)

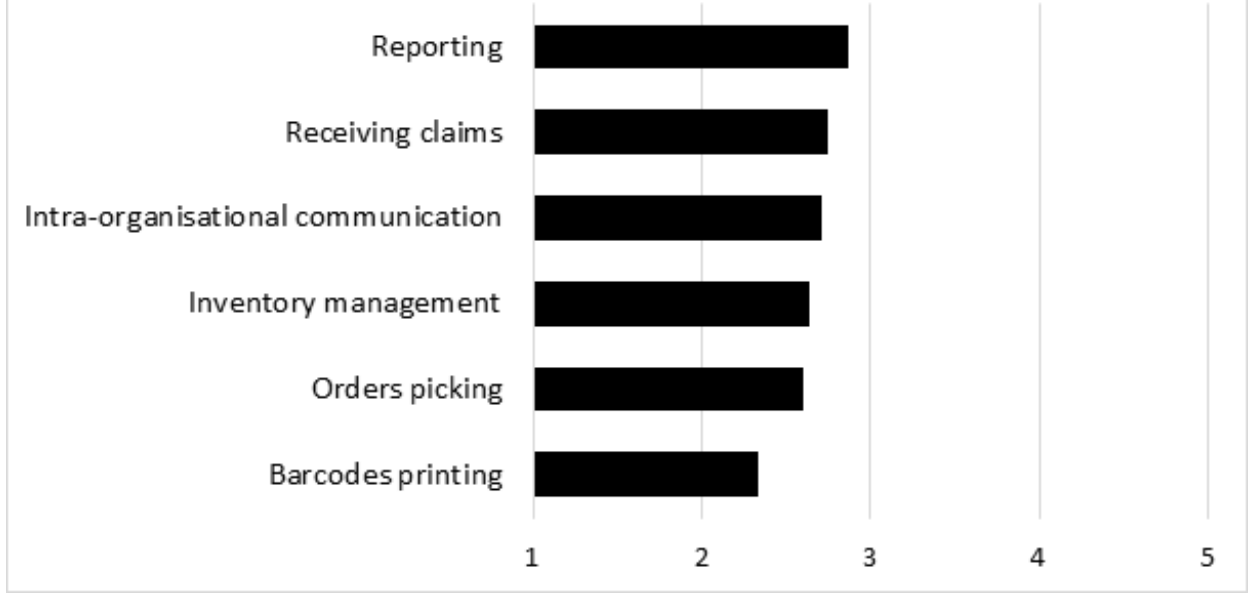

These assessments indicate that businesses resolve their problems by using other software systems or do not apply such practices at all. An interesting point is the high score given by some enterprises for the statement that their web system is the main software product in the organisation. Even those companies' answers do not differ significantly from those of the sample, and the overall degree of support of intraorganisational logistics processes is generally neutral around level (3), Neither agree nor disagree.

The last group of questions is related to the overall performance and use of web systems, and part of the results are shown in Figure 5. The data show that organisations, despite the shortcomings of their systems, are rather satisfied with them, with an average rating of (3.52), while the rating pointing to the need for improvement is only (3.15).

Figure 5. Answers to the request - Please rate the following statements about your company website (related to the support of intra-organisational logistics processes and the overall performance)

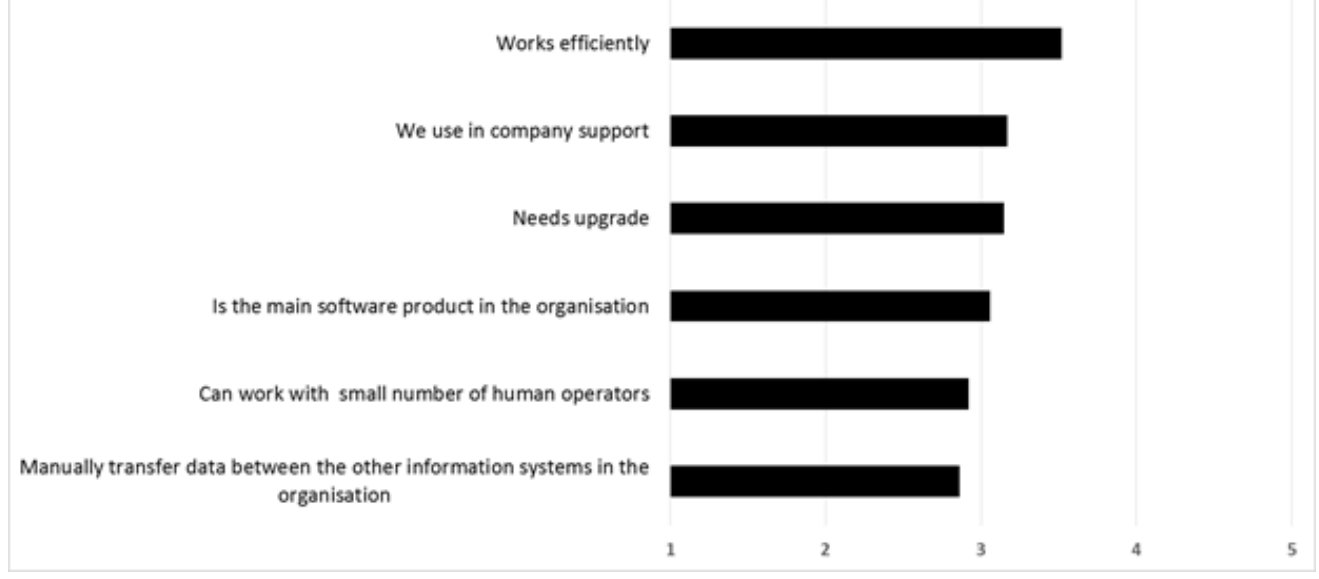




\section{Articles}

The evaluation, indicating whether the system is a core software product in the organisation, is 3.06 , which, in combination with the low estimates for manually transferring data between the other information systems in the organisation (2.86) and being able to work with low level human operators (2.92) shows the relatively low degree of use of the capabilities of this type of solution.

\section{CONCLUSION AND FUTURE WORK}

The degree of use of web practices in Bulgarian organisations is still low and unsatisfactory. The reasons for those results could be found in the nature of the competitiveness and the overall level of digitalisation and digital transformation of the business. A large number of organisations apply basic practices in the use of web-based systems, leading to a lack of opportunities for the development of modern and sustainable logistics systems. Under the influence of the global trends companies have to undertake initiatives for higher usage of web technologies in the logistics practice in order to meet the new completion challenges.

However, the main developments have been put into place, and the application of more web practices is somewhat dependent on the degree of their implementation by the other supply chain members.

The study does not claim to be exhaustive but rather outlines the main lines of development by revealing a number of guidelines for future research. Generally speaking, these research alternatives are focused on factors related to the implementation of web practices, webbased integration models in the supply chain, information systems and logistics systems sustainability, digitalisation and digital transformation of logistics activities and supply chain management. Special research areas could be defined for e-commerce and related logistics management.
Web Practices for Sustainable Development of Logistics

Systems in Bulgarian Enterprises

\section{REFERENCES}

Boyanov, L. (2019). Approaches for enhancing digitalization and digital transformation in supply chain management. Conferences of the Department Informatics, 1, 91-102.

Boysen, N., de Koster, R., \& Weidinger, F. (2018). Warehousing in the e-commerce era: A survey. European Journal of Operational Research. ejor.2018.08.023

Dragomirov, N. (2015). Information systems and technologies. Publishing Complex UNWE (in Bulgarian).

Eurostat. (2017). E-commerce statisticsStatistics Explained. https://ec.europa.eu/ eurostat/statistics-explained/index.php/Ecommerce_statistics

HCL. (2014). APl-fication Core Building Block of the Digital Enterprise. HCL. https://www. hcltech.com/white-papers/systemsintegration/api-fication-core-building-blockdigital-enterprise

Jovanović, M., Dlačić, J., \& Okanović, M. (2018). Digitalization and society's sustainable development - Measures and implications. Zbornik Radova Ekonomskog Fakulteta u Rijeci : Časopis Za Ekonomsku Teoriju i Praksu, 36(2), 905-928. https://doi.org/10.18045/ zbefri.2018.2.905

Kadłubek, M. (2015). The Selected Areas of E-logistics in Polish E-commerce. Procedia Computer Science, 65, 1059-1065. https:// doi.org/10.1016/j.procs.2015.09.052

Katrandzhiev, T. (2008). Distribution (in Bulgarian).

Kawa, A. (2017). Fulfillment service in e-commerce logistics. Logforum, 13(4), 429438. https://doi.org/10.17270/J.LOG.2017.4.4

Laudon, K. C., \& Laudon, J. P. (2012). Management information systems: Managing the digital firm (12th ed). Prentice Hall. 
Madanchian, M., \& Taherdoost, H. (2016). Perusing of Organizational Culture Effects on E-Mail Communication. Procedia Technology, 22, 1076-1083. https://doi.org/10.1016/j. protcy.2016.01.152

Papagiannidis, S., Gebka, B., Gertner, D., \& Stahl, F. (2015). Diffusion of web technologies and practices: A longitudinal study. Technological Forecasting and Social Change, 96, 308-321. https://doi.org/10.1016/j. techfore.2015.04.011

Patil, H., \& Divekar, Brig. R. (2014). Inventory Management Challenges for B2C E-commerce Retailers. Procedia Economics and Finance, 11, 561-571. https://doi.org/10.1016/S22125671(14)00221-4

PostNord. (2017). E-commerce in Europe. https://www.postnord.com/en/media/ publications/e-commerce/

Richards, G. (2014). Warehouse Management: A Complete Guide to Improving Efficiency and Minimizing Costs in the Modern Warehouse (Second edition). Kogan Page.
Saskia, S., Mareï, N., \& Blanquart, C. (2016). Innovations in e-grocery and Logistics Solutions for Cities. Transportation Research Procedia, 12, 825-835. https://doi. org/10.1016/j.trpro.2016.02.035

Slavova, M. (2016). Digital Business Transformation. Ikonomiceski i Sotsialni Alternativi, 4, 142-149 (in Bulgarian).

Veeqo. (2018). Best Warehouse Management System. Veeqo. https://www.veeqo.com/ features/warehouse-management-system

Vodenicharova, M. (2016). Application of Quality Management Systems in the Logistics Sector in Bulgaria. Economic Alternatives, 4, 515-528.

Yu, Y., Wang, X., Zhong, R. Y., \& Huang, G. Q. (2016). E-commerce Logistics in Supply Chain Management: Practice Perspective. Procedia CIRP, 52, 179-185. https://doi.org/10.1016/j. procir.2016.08.002

Żurek, J. (2015). E-commerce influence on changes in logistics processes. Logforum, 11(2), 129-138. https://doi.org/10.17270/J. LOG.2015.2.1 